\title{
PROPOSTA DE MELHORIA DA QUALIDADE DA INFORMAÇÃO DOS PROCESSOS DE GESTÃO DA INFRAESTRUTURA PREDIAL DA UNIFEI
}

\author{
QUALITY INFORMATION IMPROVEMENT PROPOSAL FOR BUILDING \\ INFRASTRUCTURE MANAGEMENT PROCESS AT UNIFEI
}

Ederson da Silva Teixeira, Universidade Federal de Itajubá,MG, Brasil E-mail: ederson.teixeira@unifei.edu.br

Fabio Favaretto

Universidade Federal de Itajubá,MG, Brasil E-mail: fabio.favaretto@unifei.edu.br

Recebido em: 16.07.2020 - Aceito em: 13.09.2020

DOI: http://dx.doi.org/10.5902/2526629248206

RESUMO: Com um volume de atendimento da ordem de 3.500 demandas de manutenção por ano, a Diretoria de Obras e Infraestrutura (DOBI) da Universidade Federal de Itajubá (UNIFEI) realiza variados e complexos processos, que, quando não estão claramente definidos, causam problemas de gestão no setor, como retrabalhos, atrasos e até mesmo a não realização de uma atividade necessária. O objetivo deste trabalho é propor melhorias na qualidade de informações, para aumentar a eficiência dos processos de manutenção da infraestrutura da UNIFEI. Para isso, foram identificadas as principais dimensões da qualidade que interferem no processo de infraestrutura, em seguida, foi mapeado o processo para a manutenção predial na UNIFEI e feitas inferências para a sua melhoria. Constatou-se que a falta da Completude é o fator mais relevante para causar retrabalhos e aumentar o número de atendimentos no banco de dados da Diretoria de Obras e Infraestrutura (DOBI). Com a implementação realizada, criando a etapa de vistoria no fluxo do processo, espera-se que não aconteçam mais retrabalhos, e, por este fator, falta da Completude, pois, a vistoria dará condições para um levantamento adequado das informações para a execução do serviço.

Palavras-chave: Processo de negócio; Mapeamento de processo; Fluxograma; Qualidade da informação.

ABSTRACT: With a service volume of around 3,500 maintenance demands per year, the Directorate of Works and Infrastructure - DOBI of the Federal University of Itajubá - UNIFEI carries out varied and complex processes, which when 
they are not clearly defined, are the cause of management problems in the sector, such as rework, delays and even the non-performance of a necessary activity. The objective of this work is to propose improvements to increase the efficiency of the maintenance processes of UNIFEl's infrastructure, through improvements in the quality of information. For this, the main dimensions of quality that interfere in the infrastructure process were identified, the process for building maintenance at UNIFEI was mapped and inferences were made in this process for its improvement. It was found that the lack of Completeness is the most relevant factor to cause rework and increase the number of calls in the database of the Directorate of Works and Infrastructure - DOBI. With the implementation that was carried out in the process, creating the inspection step in the process flow, it is expected that no further rework will take place due to this factor, lack of Completeness, as the inspection will provide conditions for adequate survey of the information for the execution of the process service.

Keywords: Business process; Process mapping; Flowchart; Information quality.

\section{INTRODUÇÃO}

O setor responsável pela gestão, planejamento, coordenação e acompanhamento de todas as atividades técnicas relacionadas a obras, reformas e serviços de manutenção dos bens imóveis do campus sede da UNIFEl é a Diretoria de Obras e Infraestrutura (DOBI).

O volume de serviços prestados pela DOBI (cerca de 3.500 atendimentos anuais em infraestrutura), e a fragilidade dos processos, causada pela falta de padronização e clareza em muitos deles, podem ocasionar retrabalhos, atrasos, e, até mesmo, impedir a realização dos trabalhos executados pela Diretoria.

O problema a ser sanado por esta pesquisa é a falta de padronização desses processos, que geram lentidão no atendimento e retrabalhos, com foco na Coordenação de Infraestrutura (CIF), que é o setor da DOBI responsável pela manutenção no campus da UNIFEI em Itajubá.

A pesquisa busca o aumento da eficiência dos processos de manutenção da infraestrutura da UNIFEI, por meio de melhorias na qualidade das informações, identificando fatores críticos no processo de gestão da infraestrutura predial e utilizando o fluxograma, como ferramenta de mapeamento de processos, para a identificação das suas falhas de gestão da infraestrutura predial da UNIFEI.

Por meio da modelagem de processos de negócio, enquanto instrumento de análise e comunicação, e com base na representação dos processos, a melhoria 
organizacional passou a se configurar como uma ferramenta relevante para a criação de uma instituição competitiva e de sucesso (Pádua, 2012).

Este trabalho possui como objetivo geral aumentar a eficiência dos processos de manutenção da infraestrutura da UNIFEI, por meio de melhorias na qualidade das informações, no Campus Professor José Rodrigues Seabra.

\section{REFERENCIAL TEÓRICO}

\subsection{Processos de negócio}

Os processos de negócio podem ser definidos, de forma prática, como a maneira pela qual alguma coisa é feita em uma organização. Por meio da dissecção das duas palavras, é possível afirmar que um negócio é uma entidade organizacional que emprega recursos para proporcionar aos clientes os produtos ou serviços desejados. Por outro lado, a palavra processo representa um conceito ambíguo, com inúmeros significados diferentes, com base no contexto em que são empregados. Para o contexto deste estudo, uma definição particularmente interessante é a de que um processo implica a transformação de inputs em outputs (Laguna \& Marklund, 2005).

Os processos envolvem, além dos inputs e outputs, também, a ordenação, os objetivos, o espaço, o tempo e os valores que, conectados de maneira lógica, resultam em uma estrutura que busca entregar os serviços e bens físicos aos clientes. Sendo assim, entender adequadamente os processos é de suma importância, pois eles representam a chave para o sucesso de qualquer negócio. Uma organização é tão efetiva quanto seus processos, uma vez que são eles os grandes responsáveis por aquilo que é oferecido ao cliente (Johansson et al., 1995).

Os processos de negócio mostram onde e em que os recursos e as competências organizacionais são aplicados em busca da geração da vantagem competitiva sustentável (Beretta, 2002). O mesmo autor afirma que a busca por essa competitividade e pelo atendimento apropriado ao cliente direcionou as organizações para uma revisão de sua estrutura, arquitetando suas atividades com base nos processos de negócios e, não mais, nas áreas funcionais.

Vale destacar, ainda, que a análise e a compreensão dos processos de negócio, de forma estruturada, permitem que as organizações se tornem menos dependentes de um grupo restrito de pessoas que, por dominarem determinados processos, acabam se tornando indispensáveis para o funcionamento da organização. As empresas que se tornam "reféns" de pessoas que detêm, exclusivamente, o domínio de determinado processo, podem acabar em situações realmente críticas quando tais pessoas estão indisponíveis para a organização (Hammer, 2001). 


\subsection{Modelagem de Processos de Negócio}

A representação por processos é de total relevância para uma organização. Para Harrington (1997), os processos apresentam variações nas organizações, devido a uma série de diferenças enfrentadas como: pessoas, instruções de gestores ou fornecedores e atividades de negócios. Isso reflete uma variação de inputs e, consequentemente, de outputs.

A Modelagem de Processos de Negócio se refere a um conjunto de fases, com o objetivo de promover os resultados esperados, considerando todas as etapas, como o aumento do entendimento acerca do processo em sua totalidade e a elevação da satisfação do cliente. Juntamente com ferramentas como ciclo PDCA, Six Sigma, Sistemas de Gestão de Qualidade e outras, a Modelagem de Processos representa um fator de extrema significância para o gerenciamento destes (Silva \& Souza, 2003).

A modelagem de processos busca verificar o alinhamento entre as atividades executadas e o objetivo do negócio (eficácia), e entre a adequação do consumo de recursos e os produtos gerados (eficiência). Ela também é uma ferramenta gerencial analítica e de comunicação (Villela, 2000).

Modelar o processo contribui significativamente para a descoberta dos componentes fundamentais e sensíveis, em que as melhorias fazem diferença, pois, a modelagem permite a compreensão dos processos de negócio existentes e futuros, e garante seu melhor desempenho (Pidd, 1998).

Segundo Davies et al. (2006), os modelos de processos de negócio expõem de maneira gráfica as atividades e a lógica do fluxo de controle constituintes do processo. Dessa forma, uma das técnicas utilizadas para a modelagem de processo é o seu mapeamento por meio do uso de fluxogramas, os quais são capazes de expor de maneira gráfica um processo, novo ou existente, além de identificar os eventos da atividade e suas sequências por meio de linhas, palavras e símbolos. A ferramenta gráfica permite a fácil visualização, não só das atividades componentes do processo, mas, também, da maneira com a qual elas se relacionam (Harrington, 1997).

\subsection{Qualidade da Informação}

Segundo Oleto (2006), a qualidade da informação ainda é um assunto muito subjetivo no campo da ciência, um desses constructos de entendimento rápido, por meio do senso comum, mas de complexo entendimento, quando se busca uma definição mais rigorosa. Por outro lado, segundo Valente e Fujino (2016), o 
avanço dos estudos sobre o tema tem resultado em sugestões de diferentes atributos, dimensões, classes, categorias ou características para atribuir qualidade à informação. E, mesmo nos casos em que se observam similaridades, tais atributos são apresentados de forma dispersa, sem definições claras e sem qualquer agrupamento mais sistemático. (Eppler \& Wittig, 2000 apud Valente \& Fujino, 2016).

$\mathrm{Na}$ visão de Eppler (2006) apud Scodeler (2019), é importante avaliar a informação por meio das dimensões de "acuracidade, precisão, manutenção e valor, que são codificados por meio do saber o que na aplicabilidade, consistência e clareza no processo de conhecimento e aprendizado e entre outras coisas".

Segundo Sordi e Meireles (2011), há muitas formas de categorização das dimensões da qualidade da informação. Huang, Lee e Wang (1999) apud Sordi e Meireles (2011), por exemplo, desenvolveram uma lista de quinze dimensões para a análise da informação, classificadas em quatro categorias, demonstradas no Quadro 1:

Quadro 1 - Categorias e dimensões de qualidade da informação

\begin{tabular}{|c|c|}
\hline Categorias & Dimensões \\
\hline Intrínseca & Acurácia, Objetividade, Credibilidade e Reputação \\
\hline Acessibilidade & Acesso e Segurança \\
\hline Contextual & $\begin{array}{c}\text { Relevância, Valor Agregado, Economia de Tempo, Completude e } \\
\text { Quantidade de Dados }\end{array}$ \\
\hline Representacional & $\begin{array}{c}\text { Interpretabilidade, Facilidade de Uso, Representação Concisa e } \\
\text { Representação Consistente }\end{array}$ \\
\hline
\end{tabular}

Fonte: Adaptado de Huang, Lee, \& Wang (1999).

Na visão de Guimarães e Évora (2004), é possível destacar uma função gerencial nas unidades funcionais, a partir de um modelo que privilegia a descentralização administrativa e técnica da unidade, a participação na tomada de decisão e o trabalho compartilhado entre os profissionais que ali atuam.

\section{MÉTODO DE PESQUISA}

\subsection{Planejamento da pesquisa ação}

Por meio da observação e acompanhamento do processo, foram identificados, até o momento, problemas como a falta de padronização dos processos; a falta de conhecimento das responsabilidades por parte dos envolvidos nos processos; o desconhecimento do fluxo processual pelos envolvidos; e a ausência de um responsável formal por cada processo.

Outro problema enfrentado na infraestrutura é a falta de um procedimento para serviços multidisciplinares, isto é, serviços nos quais se necessita o envolvimento 
de mais de um tipo de profissional (pedreiros, pintores, eletricistas, entre outros). Neste caso, o serviço pode ser executado parcialmente, apenas pelo profissional de maior relevância, fazendo com que o cliente tenha que demandar novamente os serviços da $\mathrm{DOBI}$, até mais de uma vez, para que, assim, os outros profissionais se envolvam e concluam o serviço, atendendo a necessidade do cliente.

Considerando o cenário apresentado, o mapeamento dos processos permitirá a identificação dos pontos falhos e a proposição de melhorias, corrigindo as distorções existentes e proporcionando os melhoramentos almejados. Neste estudo, daremos ênfase aos problemas da Coordenação de Infraestrutura (CIF).

\subsection{Coleta de dados}

A coleta de dados foi feita, principalmente, por meio da observação, uma vez que o pesquisador está lotado no setor há cerca de 10 anos e ocupa o cargo de Diretor de Obras e Infraestrutura há 6 anos, participando ativamente de grande parte dos processos da DOBI.

Em análise de documentos, tais como os memorandos de pedidos de serviços de infraestrutura aos quais o pesquisador tem acesso irrestrito e faz a leitura diariamente, observou-se uma recorrência de pedidos com títulos semelhantes e em locais repetidos.

Ao observar as planilhas de controle de demandas de serviços de infraestrutura da $\mathrm{DOBI}$, pode-se constatar que os dados do registro do número de atendimentos realizados em infraestrutura, não são dados confiáveis, pois o número de atendimentos, se feitos de maneira correta, deveria ser menor do que os apresentados nas planilhas de controle, apesar de não ser possível mensurar essa redução antes do resultado desta pesquisa.

Isso se dá da seguinte forma: Numa situação hipotética, um cliente faz uma solicitação de mudança de uma sala, com a remoção de uma parede para a ampliação da sala; numa triagem inicial, realizada por uma assistente administrativa, essa demanda é classificada como da área civil e assim é encaminhada para o Assistente da Coordenação de Infraestrutura, responsável pelas demandas da área civil; o assistente, por sua vez, dimensiona uma equipe operacional para realizar o trabalho que envolverá, basicamente, pedreiros e ajudantes, pois, trata-se da remoção de uma parede; ao demolir a parede, a equipe encontra uma instalação elétrica que estava embutida nela. Como nessa equipe não foi incluído um eletricista, eles deixam o eletroduto e a fiação no local, terminam a remoção da parede e, aqui acontece o maior erro neste processo, pois, dão o serviço como 
concluído; a Ordem de Serviço é encerrada e, invariavelmente, o cliente faz uma nova solicitação para a remoção da instalação elétrica. Novamente, na triagem, essa demanda é classificada como sendo da área elétrica e, assim, é encaminhada ao Coordenador de Infraestrutura, que é responsável pelas demandas da área elétrica; o coordenador dimensiona uma equipe operacional para realizar o trabaIho e o ciclo se repete. Este ciclo irá se repetir "N" vezes, conforme demonstrado na Figura 1, para todas as demandas que surgirem decorrentes daquela solicitação inicial do cliente, sempre que ocorrer algum serviço para o qual a equipe não esteja devidamente dimensionada, considerando cada etapa complementar como um novo serviço.

A Figura 1 ilustra de maneira simplificada o mapa de processo de serviços de infraestrutura, da forma como foi apresentado no exemplo acima. Este mapa não mostra o retrabalho, pois, para a $\mathrm{DOBI}$, o serviço é dado como concluído ao final deste processo.

Para mapear este processo, foram feitas entrevistas não estruturadas com os colaboradores da coordenação de infraestrutura: assistente de administração (responsável pela triagem dos pedidos de manutenção e lançamento de dados nas planilhas de controle); técnica em eletrotécnica (responsável pelo lançamento e controle dos dados nas planilhas); assistente da coordenação de infraestrutura (responsável pelo gerenciamento dos serviços de manutenção da área Civil); coordenador de infraestrutura (responsável pelo gerenciamento dos serviços de manutenção da área elétrica e de refrigeração, além da coordenação geral do setor); e a administradora da DOBI (responsável pelo gerenciamento macro dos projetos). 


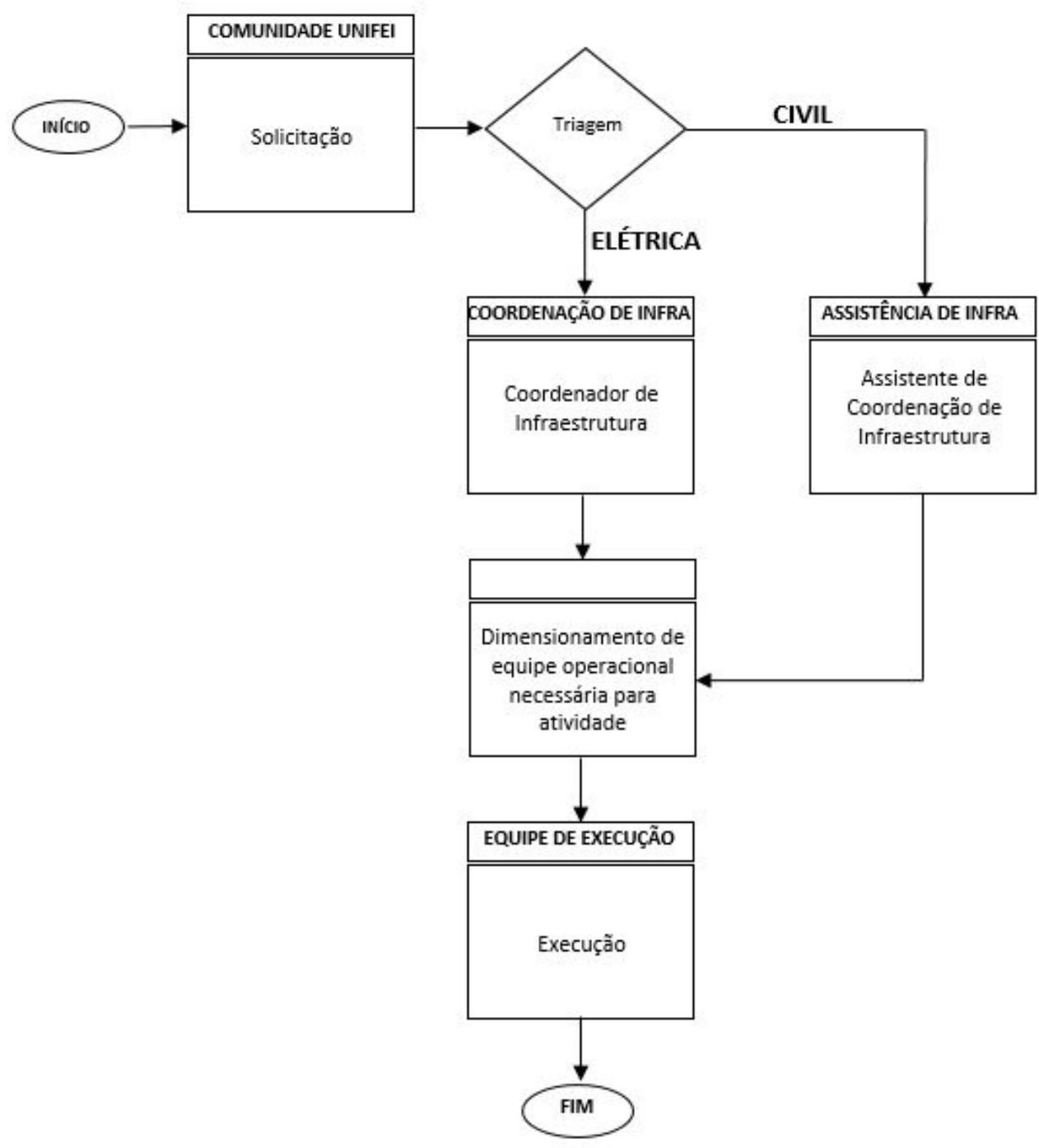

Figura 1 - Mapa do processo de serviços de infraestrutura Fonte: Elaborado pelo autor (2020).

Toda essa dinâmica, além de gerar retrabalhos, tanto na triagem, na área administrativa e no operacional, também demanda muito mais tempo para a conclusão da solicitação do cliente e ainda gera retrabalho a ele, que precisa fazer as solicitações necessárias, até que a sua demanda seja atendida por completo. Assim, a criação de um procedimento para o atendimento de serviços multidisciplinares deverá corrigir esta distorção.

Além disso, foram feitas entrevistas não estruturadas, em reuniões que aconteceram semanalmente com os servidores da $\mathrm{DOBI}$, para acompanhamento 
de Processos de Compras e andamento dos serviços de obras e infraestrutura. Foram realizadas, ainda, reuniões entre a Diretoria de Obras e Infraestrutura (DOBI) com outras diretorias, como a Diretoria de Compras e Contratos (DCC) e a Diretoria de Contabilidade e Finanças (DCF), a fim de criar procedimentos conjuntos entre essas diretorias, para processos que envolvem interação entre elas, e para orientar os fiscais de contratos quanto a sua atuação.

Portanto, os dados foram coletados por meio da observação do pesquisador, das entrevistas não estruturadas com os colaboradores da DOBI, nas planiIhas de controle de dados da Coordenação de Infraestrutura e por meio do mapeamento do processo, utilizando o fluxograma, o qual aponta as necessidades de melhorias em cada processo. No caso da Infraestrutura, os dados do volume de atendimentos anuais não poderão ser aproveitados, uma vez que não refletem a realidade do número de atendimentos, como já explicado anteriormente, portanto, as melhorias nos processos permitirão, ora em diante, acumular dados confiáveis para as tomadas de decisões futuras.

Para maior eficácia deste estudo, foram catalogadas quatro solicitações de serviços (processos), dos diferentes tipos - infraestrutura civil, elétrica e refrigeração - conforme observamos no Quadro 2, para que se possa proceder a análise da qualidade da informação em cada uma delas.

Quadro 2 - Solicitações de serviços de infraestrutura

\begin{tabular}{|c|c|c|c|c|c|c|}
\hline $\begin{array}{c}\text { PRO- } \\
\text { CESSO }\end{array}$ & MEMORANDO & ITEM & TIPO & SOLICITAÇÃO & $\begin{array}{c}\text { CAMI- } \\
\text { NHO }\end{array}$ & OBSERVAÇÃO \\
\hline 1 & $419 / 2017-I M C$ & $\begin{array}{c}\text { Ar con- } \\
\text { dicio- } \\
\text { nado }\end{array}$ & $\begin{array}{c}\text { Refrige- } \\
\text { ração }\end{array}$ & $\begin{array}{c}\text { Liberação do técnico de } \\
\text { refrigeração para a con- } \\
\text { clusão da instalação do ar } \\
\text { condicionado na sala 3-29 } \\
\text { no bloco X2. }\end{array}$ & $\begin{array}{c}\text { Coorde- } \\
\text { nação }\end{array}$ & Concluído. \\
\hline 2 & $239 / 2017-I R N$ & $\begin{array}{c}\text { Rede } \\
\text { elétrica }\end{array}$ & Elétrica & $\begin{array}{c}\text { Manutenção na instala- } \\
\text { ção elétrica da sala do } \\
\text { Simulador, localizada no } \\
\text { primeiro piso do prédio do } \\
\text { IMC, sendo necessária a } \\
\text { revisão da instalação de } \\
\text { lâmpadas e interruptores, } \\
\text { além das tomadas. }\end{array}$ & $\begin{array}{c}\text { Coorde- } \\
\text { nação }\end{array}$ & $\begin{array}{c}\text { Encaminhado memo- } \\
\text { rando solicitando a } \\
\text { informação de dados } \\
\text { complementares para a } \\
\text { instalação de tomadas, } \\
\text { iluminação, de acordo } \\
\text { com os usuários e o tipo } \\
\text { de atividade. }\end{array}$ \\
\hline 3 & $201 / 2017-I R N$ & Gotei- & Civil & $\begin{array}{c}\text { Instalação de insulfilm } \\
\text { branco leitoso na porta de } \\
\text { vidro da sala de aula pós- } \\
\text {-graduação L8.1.09, no } \\
\text { bloco I8, e no vidro entre } \\
\text { a sala L8.1.08 bloco L8 e } \\
\text { insulfilm 30\% nos vidros } \\
\text { das cinco claraboias do } \\
\text { bloco M3. }\end{array}$ & $\begin{array}{c}\text { Assis- } \\
\text { tência da } \\
\text { coorde- } \\
\text { nação }\end{array}$ & $\begin{array}{c}\text { Respondido p/IRN - o } \\
\text { material e a mão de } \\
\text { obra serão contratados } \\
\text { por meio de processo } \\
\text { licitatório. }\end{array}$ \\
\hline
\end{tabular}




\begin{tabular}{|l|l|l|l|l|l|l|}
\hline 4 & 239/2017-IRN & $\begin{array}{l}\text { Pelícu- } \\
\text { la pro- } \\
\text { tetora } \\
\text { insul- } \\
\text { film }\end{array}$ & Civil & $\begin{array}{l}\text { Sanar problemas de gotei- } \\
\text { ra no corredor central, en- } \\
\text { trada de água pela tubula- } \\
\text { ção do ar condicionado da da } \\
\text { sala 7. }\end{array}$ & $\begin{array}{l}\text { Os problemas de gotei- } \\
\text { cia da dentro do CEQUAN } \\
\text { coorde- } \\
\text { ração } \\
\text { estão ocorrendo pelo } \\
\text { fato de estar infiltrando } \\
\text { água por dentro da man- } \\
\text { ta da laje. OBS. o servi- } \\
\text { dor Eduardo (DOB) ana- } \\
\text { lisou o local juntamente e } \\
\text { observou o problema. Já } \\
\text { foi comunicado à cliente, } \\
\text { as causas da infiltração. } \\
\text { resp. Foi colocado veda } \\
\text { calha e manta asfáltica } \\
\text { no local, para evitar que } \\
\text { infiltre muita água, mas } \\
\text { não resolverá o proble- } \\
\text { ma por definitivo. }\end{array}$ \\
\hline
\end{tabular}

Fonte: Elaborado pelo autor (2017).

Ao fazer a análise do Quadro 2, pode se observar quatro diferentes tipos de serviços (processos) e os diferentes encaminhamentos que cada um deles recebeu.

Ao examinar a coluna SOLICITAÇÃO e comparar com a coluna OBSERVAÇÃO, no Quadro 3, pode se observar os problemas dos processos, que podem ser corrigidos com a melhoria da Qualidade da Informação. Ao observar o mapa do processo, é possível verificar a etapa de vistoria, que deverá fornecer o subsídio necessário para a boa qualidade da informação e, assim, permitir o seu fluxo natural.

À luz da qualidade da informação, elencamos as dimensões da qualidade, apresentadas no Quadro 1, mais importantes para esta pesquisa-ação, sendo elas: Objetividade; Completude; Interpretabilidade; Representação concisa; Representação consistente.

Optou-se por trabalhar com essas dimensões por entender que elas colaboram com o trabalho, conforme as definições dessas dimensões, explicitadas por Kahn, Strong e Wang, (2002) apud Trindade e Oliveira (2007), temos:

- Objetividade: também conhecido como imparcialidade, este critério é referente a não contaminação de um conteúdo informacional por visões ou interesses particulares;

- Completude: se relaciona à integridade e suficiência de um conteúdo;

- Interpretabilidade: a informação está na linguagem e nos símbolos apropriados e as definições estão claras;

- Representação concisa: a informação é apresentada de forma compacta;

- Representação consistente: este critério possibilita a avaliação da estruturação formal, consistência e condições de leitura de uma determinada fonte de informação. 
Para cada uma destas dimensões, definimos uma escala de 1 a 5 , em que o 1 é o mais distante e o 5 é o mais próximo, e cada informação atende cada dimensão, conforme demonstrado no Quadro 3, a seguir. Os valores 2 e 4 são intermediários entre seus antecessores e sucessores.

Quadro 3 - Escala das dimensões

\begin{tabular}{|c|c|c|c|c|c|}
\hline & Nota & & & & \\
\hline Dimensão & 1 & 2 & 3 & 4 & 5 \\
\hline Objetividade & $\begin{array}{l}\text { Informação conta- } \\
\text { minada, totalmente } \\
\text { parcial. }\end{array}$ & & $\begin{array}{l}\text { In forma ção } \\
\text { parcialmente } \\
\text { contaminada, } \\
\text { tendenciosa. }\end{array}$ & & $\begin{array}{l}\text { Informação pura } \\
\text { e imparcial. }\end{array}$ \\
\hline Completude & $\begin{array}{l}\text { Informação total- } \\
\text { mente incompleta. }\end{array}$ & & $\begin{array}{l}\text { In fo r m a ç ã o } \\
\text { parcial. }\end{array}$ & & $\begin{array}{l}\text { Informação com- } \\
\text { pleta, suficiente. }\end{array}$ \\
\hline Interpretabilidade & $\begin{array}{l}\text { Informação confusa, } \\
\text { incompreensível. }\end{array}$ & & $\begin{array}{l}\text { Informação não } \\
\text { muito clara. }\end{array}$ & & $\begin{array}{l}\text { Informação clara, } \\
\text { de fácil entendi- } \\
\text { mento. }\end{array}$ \\
\hline $\begin{array}{l}\text { Representação } \\
\text { concisa }\end{array}$ & $\begin{array}{l}\text { Informação excessi- } \\
\text { va. }\end{array}$ & & $\begin{array}{l}\text { Informação nu- } \\
\text { merosa. }\end{array}$ & & $\begin{array}{l}\text { Informação com- } \\
\text { pacta, estritamen- } \\
\text { te o necessário. }\end{array}$ \\
\hline $\begin{array}{l}\text { Representação } \\
\text { consistente }\end{array}$ & $\begin{array}{l}\text { Informação deses- } \\
\text { truturada, sem pa- } \\
\text { drão, confusa. }\end{array}$ & & $\begin{array}{l}\text { Informação le- } \\
\text { vemente de- } \\
\text { sestruturada. }\end{array}$ & & $\begin{array}{l}\text { Informação estru- } \\
\text { turada, no mes- } \\
\text { mo formato. }\end{array}$ \\
\hline
\end{tabular}

Fonte: Elaborada pelo autor (2020).

As dimensões da Qualidade da Informação mais importantes para esta pesquisa-ação, identificadas pelo autor, com suas respectivas avaliações e considerando a escala definida no Quadro 3, estão apresentadas no Quadro 4. A somatória das notas em cada dimensão demonstra as principais dimensões que devem ser trabalhadas para a melhoria na Qualidade da Informação. Doravante, serão tratadas as duas que obtiverem as menores notas nas somatórias do Quadro 4. Esses dados foram obtidos nas entrevistas não estruturadas com os colaboradores da CIF e as informações foram validadas pelo gestor do processo.

Quadro 4 - Medição da qualidade da informação - dimensão X processo

\begin{tabular}{|c|c|c|c|c|c|}
\hline Dimensão & Processo 1 & Processo 2 & Processo 3 & Processo 4 & Somatória \\
\hline Objetividade & 5 & 5 & 5 & 5 & $\mathbf{2 0}$ \\
\hline Completude & 3 & 2 & 3 & 4 & $\mathbf{1 2}$ \\
\hline Interpretabilidade & 5 & 5 & 5 & 5 & $\mathbf{2 0}$ \\
\hline $\begin{array}{c}\text { Representação } \\
\text { concisa }\end{array}$ & 5 & 3 & 5 & 5 & $\mathbf{1 8}$ \\
\hline $\begin{array}{c}\text { Representação } \\
\text { consistente }\end{array}$ & 5 & 5 & 5 & 5 & $\mathbf{2 0}$ \\
\hline
\end{tabular}

Fonte: Elaborado pelo autor (2020). 


\subsection{Análise dos dados}

O caso hipotético apresentado anteriormente, conforme o mapa ilustrado na Figura 1, demonstra problemas no processo, porque, além dos retrabalhos gerados - como demora excessiva no atendimento da solicitação e poluição dos dados de atendimentos, o que impossibilita um correto relatório de gestão - acarreta, também, a insatisfação do cliente, que é quem acaba gerindo o processo, pois, dele terá que partir cada solicitação para cada uma das interferências encontradas pela equipe.

De forma mais abrangente, as falhas encontradas nos processos são problemas porque, se não forem detectadas a tempo, podem gerar consequências como dificuldades na tramitação dos processos, problemas administrativos no setor e em outros órgãos da autarquia, prejuízos às empresas contratadas, prejuízo ao erário público e, até mesmo, responsabilização pessoal de servidores públicos.

Para definir as principais dimensões da qualidade da informação nos processos de manutenção da infraestrutura da UNIFEl é preciso analisar o Quadro 5.

Ao fazer a somatória das notas atribuídas às dimensões da Qualidade da Informação que estão sendo analisadas, verifica-se que a Completude e a Representação Concisa são as dimensões que apresentam as menores notas, ou seja, são as principais dimensões da Qualidade da Informação que precisam de melhoramento para obtenção de maior eficiência nos processos de Infraestrutura da DOBI.

Explorando os quatro processos apresentados no Quadro 2, com base nas dimensões mais deficitárias encontradas no Quadro 4, temos a análise apresentada no Quadro 5.

Quadro 5 - Análise dos processos em relação às dimensões que serão trabalhadas

\begin{tabular}{|c|c|c|c|c|}
\hline PROC. & SOLICITAÇÃO & OBSERVAÇÃO & DIMENSÃO & ANÁLISE \\
\hline \multirow[t]{2}{*}{1} & \multirow[t]{2}{*}{$\begin{array}{l}\text { Liberação do técni- } \\
\text { co de refrigeração } \\
\text { para a conclusão } \\
\text { da instalação do ar } \\
\text { condicionado na } \\
\text { sala } 3-29 \text { no bloco } \\
\text { X2. }\end{array}$} & \multirow[t]{2}{*}{ Concluído. } & Completude & $\begin{array}{l}\text { Trata-se de um aten- } \\
\text { dimento anterior que } \\
\text { ficou inacabado. O cor- } \\
\text { reto seria atender esta } \\
\text { solicitação, comple- } \\
\text { mentando a Ordem de } \\
\text { Serviço anterior, e não } \\
\text { abrir uma nova Ordem } \\
\text { de Serviço. Esta nova } \\
\text { OS polui os dados do } \\
\text { controle de atendimen- } \\
\text { tos. } \\
\end{array}$ \\
\hline & & & $\begin{array}{l}\text { Representa- } \\
\text { ção Concisa }\end{array}$ & $\begin{array}{l}\text { O texto não está poluí- } \\
\text { do, não mistura assun- } \\
\text { tos alheios á demanda. }\end{array}$ \\
\hline
\end{tabular}




\begin{tabular}{|c|c|c|c|c|}
\hline \multirow[t]{2}{*}{2} & \multirow{2}{*}{$\begin{array}{c}\text { Manutenção na ins- } \\
\text { talação elétrica da } \\
\text { sala do Simulador, } \\
\text { localizada no pri- } \\
\text { meiro piso do prédio } \\
\text { do IMC, sendo ne- } \\
\text { cessária a revisão } \\
\text { da instalação de } \\
\text { lâmpadas e inter- } \\
\text { ruptores, além das } \\
\text { tomadas. }\end{array}$} & \multirow{2}{*}{$\begin{array}{l}\text { Encaminhado } \\
\text { memorando } \\
\text { solicitando, in- } \\
\text { formar dados } \\
\text { complementares } \\
\text { para a instalação } \\
\text { de tomadas e } \\
\text { iluminação - de } \\
\text { acordo com os } \\
\text { usuários e tipo } \\
\text { de atividade. }\end{array}$} & Completude & $\begin{array}{c}\text { Solicitação de "manu- } \\
\text { tenção", entretanto, se } \\
\text { tratava de uma reforma } \\
\text { na rede elétrica. As in- } \\
\text { formações necessárias } \\
\text { poderiam vir anexas } \\
\text { nesta solicitacão. }\end{array}$ \\
\hline & & & $\begin{array}{l}\text { Representa- } \\
\text { ção Concisa }\end{array}$ & $\begin{array}{l}\text { O texto não mistura } \\
\text { assuntos alheios á } \\
\text { demanda, entretanto, } \\
\text { tenta trazer um diag- } \\
\text { nóstico do problema. }\end{array}$ \\
\hline \multirow[b]{2}{*}{3} & \multirow{2}{*}{$\begin{array}{c}\text { Instalação de insul- } \\
\text { film branco leitoso } \\
\text { na porta de vidro da } \\
\text { sala de aula pós- } \\
\text {-graduação L8.1.09 } \\
\text { no bloco } 18 \text { e no } \\
\text { vidro entre a sala } \\
\text { L8.1.08 bloco L8 e } \\
\text { insulfilm 30\% nos } \\
\text { vidros das cinco } \\
\text { claraboias do bloco } \\
\text { M3. }\end{array}$} & \multirow{2}{*}{$\begin{array}{l}\text { Respondido p/ } \\
\text { IRN - material e } \\
\text { mão de obra se- } \\
\text { rão contratados } \\
\text { através de pro- } \\
\text { cesso licitatório. }\end{array}$} & Completude & $\begin{array}{l}\text { Esta solicitação não } \\
\text { traz as informações ne- } \\
\text { cessárias para o aten- } \\
\text { dimento da demanda. }\end{array}$ \\
\hline & & & $\begin{array}{l}\text { Representa- } \\
\text { ção Concisa }\end{array}$ & $\begin{array}{l}\text { O texto não está poluí- } \\
\text { do, não mistura assun- } \\
\text { tos alheios á demanda. }\end{array}$ \\
\hline \multirow[t]{2}{*}{4} & \multirow[t]{2}{*}{$\begin{array}{l}\text { Sanar problemas de } \\
\text { goteira no corredor } \\
\text { central, entrada de } \\
\text { água pela tubulação } \\
\text { do ar condicionado } \\
\text { da sala } 7 .\end{array}$} & \multirow{2}{*}{$\begin{array}{l}\text { Os problemas de } \\
\text { goteiras dentro } \\
\text { do CEQUAN } \\
\text { estão ocorren- } \\
\text { do pelo fato de } \\
\text { estar infiltrando } \\
\text { água por dentro } \\
\text { da manta da laje. } \\
\text { OBS. o servidor } \\
\text { Eduardo (DOB) } \\
\text { analisou o lo- } \\
\text { cal juntamente } \\
\text { e observou o } \\
\text { problema. Já } \\
\text { foi comunicado } \\
\text { à profo Márcia } \\
\text { Kondo as causas } \\
\text { da infiltração. } \\
\text { resp. Foi coloca- } \\
\text { do veda calha e } \\
\text { manta asfáltica } \\
\text { no local para } \\
\text { evitar que infiltre } \\
\text { muita água, mas } \\
\text { não resolverá o } \\
\text { problema por de- } \\
\text { finitivo. }\end{array}$} & Completude & $\begin{array}{l}\text { Esta solicitação infor- } \\
\text { ma a necessidade do } \\
\text { cliente, que é eliminar } \\
\text { a infiltração, entretanto, } \\
\text { a origem da infiltração } \\
\text { não é aquela que apa- } \\
\text { renta para o cliente. } \\
\text { Assim, a solicitação } \\
\text { não traz todas as infor- } \\
\text { mações necessárias } \\
\text { para o atendimento da } \\
\text { demanda, pois, não in- } \\
\text { forma a origem correta } \\
\text { do problema e nem as } \\
\text { condições para a reali- } \\
\text { zação do serviço. } \\
\end{array}$ \\
\hline & & & $\begin{array}{l}\text { Representa- } \\
\text { ção Concisa }\end{array}$ & $\begin{array}{l}\text { O texto não está poluí- } \\
\text { do, não mistura assun- } \\
\text { tos alheios á demanda. }\end{array}$ \\
\hline
\end{tabular}

Nota: Fonte: elaborado pelo autor (2020). 
Isto posto, a maneira proposta para a melhoria da Qualidade da Informação para a execução dos processos de manutenção da infraestrutura, otimizando o tempo de atendimento e o racionamento dos recursos, é acrescentar ao processo uma etapa de vistoria para a verificação da necessidade do cliente. Na visão do pesquisador, isso possibilitará um levantamento preciso das informações necessárias ao processo.

\subsection{Implementação}

Considerando que o efetivo existente na DOBI é enxuto, propõe-se a inclusão do cargo de Encarregado no efetivo do contrato de mão de obra continuada (terceirizados). Como este cargo não faz parte do atual contrato, sua inclusão repercute em aumento de gasto com o contrato de mão de obra continuada. Assim, esta solução passa pela autorização da alta administração da Universidade, pois envolve o planejamento e a alocação de recursos para o referido contrato.

A solução apresentada foi apreciada e aceita pela administração da Universidade. Também foi instaurado, em 2019, o processo administrativo para o novo contrato de prestação de serviços de mão de obra continuada, com as devidas alterações no Termo de Referência para a inclusão deste novo posto de trabalho, no entanto, a licitação fracassou por duas vezes consecutivas, devido a problemas alheios à administração. Em 2020, um novo processo foi instaurado e a licitação está em curso, concomitante à apresentação deste estudo.

Assim, foi desenvolvido o novo mapa do processo dos serviços de manutenção da infraestrutura da UNIFEI, em que aparece a etapa de "vistoria no local da realização do serviço". No fluxograma é possível observar que o processo ficou bem mais enxuto e sem tomadas de decisão com critérios subjetivos.

A vistoria será realizada por pessoal técnico - colaboradores da DOBI - e possibilitará a verificação da real necessidade do cliente e sua dimensão, as interferências e as necessidades para o atendimento da demanda, o dimensionamento da equipe de trabalho, a especificação e estimativa de quantidade dos materiais a serem utilizados e o planejamento de um cronograma para a execução do serviço, quando necessário. Isto possibilitará inserir no processo uma informação com Completude e Representação Concisa.

As diretrizes para esta vistoria são:

- Verificar a pertinência da demanda;

- Verificar a viabilidade de atendimento;

- Verificar as interferências entre as áreas civil, elétrica e de refrigeração. 
A verificação das interferências entre as áreas civil, elétrica e de refrigeração é a principal diretriz, que possibilitará obtenção da Completude da informação, pois, conforme o exemplo hipotético mencionado anteriormente, no momento da vistoria, realizada no local do serviço para a remoção de uma parede ou para a ampliação de uma sala, a demanda é classificada como da área civil, porém, as interferências da parte elétrica, tais como a existência de eletrodutos e de pontos elétricos embutidos na alvenaria, são apontadas e registradas na Ordem de Serviço para o correto dimensionamento da equipe operacional. O serviço é realizado e só então a Ordem de Serviço é encerrada, evitando que o cliente precise fazer uma nova solicitação para a remoção da instalação elétrica.

O fluxo do processo se dará da seguinte forma: A DOBI recebe um memorando, no qual um cliente faz uma solicitação de serviço de infraestrutura; o assistente administrativo registra o recebimento e emite uma Ordem de Serviço - OS - para a Coordenação de Infraestrutura - CIF -; um técnico designado na CIF vai até o local onde foi solicitado o serviço e faz uma vistoria, seguindo as diretrizes apresentadas; a coordenação da CIF analisa se há impedimentos para a realização do serviço; caso houver, verifica-se qual é e direciona-se o pedido para o seu fluxo específico. Os impedimentos podem ser: memorandos duplicados; não serem de responsabilidade da CIF; ou, materiais indisponíveis para o atendimento da demanda. Caso não houver impedimento: a coordenação da CIF disponibiliza o material; a equipe operacional executa o serviço; o encarregado da equipe devolve a OS preenchida; a coordenação da CIF confere o serviço executado; os responsáveis apõem suas assinaturas na OS; a OS é finalizada e arquivada e a planilha de controle é alimentada com os novos dados.

O impacto esperado por este estudo é que, com a melhoria da qualidade da informação, aconteçam menos retrabalhos na DOBI, especialmente na Coordenação de Infraestrutura. Além disso, espera-se a diminuição do retrabalho para os clientes, uma vez que eles terão suas demandas atendidas em decorrência de uma única solicitação. Consequentemente, o tempo de atendimento das demandas de infraestruturas deverá diminuir.

\section{APRESENTAÇÃO E DISCUSSÃO DOS RESULTADOS}

Em síntese, é possível concluir que, ao mapear o processo com a utilização do fluxograma, identificam-se as falhas no processo de gestão da infraestrutura predial da UNIFEI e, ao melhorar a Qualidade da Informação e aperfeiçoar o atendimento, nota-se a melhoria na eficiência da Coordenação de Infraestrutura da DOBI. 
Considerando que, para a implementação do novo procedimento, incluindo, principalmente, uma etapa de "vistoria", foi necessária uma mudança no contrato de mão de obra continuada, para a inclusão de cargo ao encarregado efetivo do pessoal de apoio da DOBI. Esta mudança foi feita no Termo de Referência para o edital e foi realizada a licitação em 2019, porém, este certame fracassou. Em 2020, uma nova licitação foi instaurada, processo este que se encontra, na data de conclusão deste trabalho, ainda em fase de análise das propostas das licitantes para a efetivação do novo contrato.

Ademais, há que se considerar ainda, a situação de emergência de saúde pública de importância internacional decorrente da COVID-19, que está acontecendo concomitante a este trabalho, o que fez com que as demandas por serviços de manutenção na infraestrutura da UNIFEI reduzissem consideravelmente.

Destarte, não é possível comparar o número de atendimentos neste período de 2020, com os mesmos períodos de anos anteriores, porque o volume de atendimentos de demandas de manutenção está totalmente atípico, devido à consideração anterior.

Entretanto, o objetivo geral do estudo foi atingido, pois, foram implantadas mudanças, que causaram o aumento da eficiência dos processos de manutenção da infraestrutura da UNIFEI. Apesar de não haver uma comprovação numérica, pelos motivos expostos que levaram à diminuição do número de atendimentos neste período.

Com relação aos objetivos específicos, foram identificados os fatores críticos no processo de gestão da infraestrutura predial no Campus Professor José Rodrigues Seabra, sendo possível elaborar a proposta de melhoria na coleta de dados e aprovar a sua forma de implementação, o que está em andamento.

Identificaram-se, também, as principais dimensões da qualidade, o mapeamento e a melhoria do processo para manutenção predial na UNIFEI. Constatou-se que a falta da Completude é o fator mais relevante para causar retrabalhos e aumentar o número de atendimentos no banco de dados da DOBI.

Com a implementação realizada, criando a etapa de vistoria no fluxo do processo, espera-se que não aconteçam mais retrabalhos, por este fator, e falta da Completude, pois, a vistoria dará condições para o levantamento adequado das informações para a execução do serviço.

\section{CONSIDERAÇÕES FINAIS}

Este estudo irá contribuir para que setores de manutenção nos mais diversos órgãos possam melhorar a qualidade da informação e otimizar seus recursos para o atendimento de suas demandas. 
Assim, este estudo não esgota o tema e futuros estudos poderão ampliar a pesquisa, considerando outras dimensões da Qualidade da Informação ou utilizando outras ferramentas de gestão para aumentar a eficiência dos processos de manutenção.

\section{REFERÊNCIAS}

Beretta, S. (2002). Unleashing the integration potential of ERP System. Business Process Management Journal, v.8, n.3, p. 254-277.

Davies, I., Green, P., Rosemann, M., Indulska, M., \& Gallo, S. (2006). How do practitioners use conceptual modeling in practice? Data \& Knowledge Engineering, 58(3), 358-380.

Guimarães E. M. P. \& Évora Y. D. M. (2004). Sistema de informação: instrumento para tomada de decisão no exercício da gerência. Ci. Inf., 33(1), 72-80 Sistema de informação: instrumento para tomada de decisão no exercício da gerência (scielo.br).

Harrington, H. J. (1997). Aperfeiçoando processos empresariais. São Paulo: Makron Books.

Hammer, M. A. (2001). agenda: o que as empresas precisam fazer para dominar essa década. Rio de Janeiro: Campus.

Johansson, H. J., Mchug, P., Pedlebury, A. J., \& Wheller, W. A. (1995). Processos de negócios. São Paulo: Pioneira.

Laguna, M., \& Marklund, J. (2005). Business Process Modeling, Simulation and Design. New Jersey: Pearson Prentice Hall.

Oleto, R. R. (2006). Percepção da qualidade da informação. Ci. Inf., 35(1), 57-62 Percepção da qualidade da informação (scielo.br).

Pádua, S. I. D. (2012). Estudo sobre a aplicação do método de avaliação do modelo de processo de negócio do EKD. Produção, 22(1), 155-172 Estudo sobre a aplicação do método de avaliação do Modelo de Processos de $\mathrm{Ne}$ gócio do EKD (prod.org.br).

Pidd, M. (1998). Modelagem empresarial: ferramentas para a tomada de decisão. Porto Alegre: Artes Médicas.

Scodeler, M. R. (2019). Proposta de melhoria na qualidade da informação do processo de importação de componentes eletrônicos do polo tecnológico de Santa Rita do Sapucaí - um estudo de caso. (Dissertação de Mestrado, Universidade Federal de Itajubá, Itajubá, MG).

Silva, M. A. C., \& Souza, R. (2003). Gestão do processo de projeto de edificações. São Paulo: O Nome da Rosa. 
Sordi, J. O., \& Meireles, M. (2011). Dimensões de Qualidade da Informação como Elemento Classificatório para Localidades com Concentração de Atividades da Cadeia Produtiva. Anais do Encontro Associação Nacional de Pós-Graduação e Pesquisa em Administração - ENANPAD. Rio de Janeiro, RJ.

Trindade, A. L. B., \& Oliveira, M. (2007). Atributos Para Avaliação da Qualidade da Informação em Sistemas de Gestão do Conhecimento. Anais do Encontro de Administração da Informação - ENADI. Florianópolis, SC.

Valente N. T. Z., \& Fujino A. (2016). Atributos e dimensões de qualidade da informação nas Ciências Contábeis e na Ciência da Informação: um estudo comparativo. Perspectivas em Ciência da Informação, 21(2), 141-167 Atributos e dimensões de qualidade da informação nas Ciências Contábeis e na Ciência da Informação: um estudo comparativo (scielo.br).

Villela, C. S. S. (2000). Mapeamento de processos como ferramenta de reestruturação e aprendizado organizacional. Dissertação de mestrado, Universidade Federal de Santa Catarina. Florianópolis, SC. 